\title{
Hyperspectral Evaluation of Venturia inaequalis Management Using the Disease Predictive Model RIMpro in the Northeastern U.S.
}

\author{
Matthew Wallhead ${ }^{1,2}$, Heping Zhu², Kirk Broders ${ }^{1,3}$ \\ ${ }^{1}$ Department of Biological Sciences, University of New Hampshire, Durham, USA \\ ${ }^{2}$ U.S. Department of Agriculture-Agriculture Research Service, Application Technology Research Unit, Wooster, USA \\ ${ }^{3}$ Department of Bioagricultural Sciences and Pest Management, Colorado State University, Fort Collins, USA \\ Email: matthew.wallhead@ars.usda.gov
}

How to cite this paper: Wallhead, M., Zhu, H.P. and Broders, K. (2017) Hyperspectral Evaluation of Venturia inaequalis Management Using the Disease Predictive Model RIMpro in the Northeastern U.S. Agricultural Sciences, 8, 1358-1371.

https://doi.org/10.4236/as.2017.812098

Received: November 4, 2017

Accepted: December 26, 2017

Published: December 29, 2017

Copyright $\odot 2017$ by authors and Scientific Research Publishing Inc. This work is licensed under the Creative Commons Attribution International License (CC BY 4.0).

http://creativecommons.org/licenses/by/4.0/

\begin{abstract}
Use of hyperspectral spectroradiometers allows for information on different light bands to be captured, allowing for identification of plant health status. Apple scab is the most important disease in the production of apples. RIMpro is a web-based decision support system (DDS) for orchardists that has the capacity to improve optimal fungicide application for the control of apple scab and has the potential to reduce the number of applications and thereby reduce input expenses. The objective of this study was to complete a hyperspectral assessment of apple leaves in order to evaluate the spectral characteristics of trees sprayed according to forecasted infection events from the DDS. No significant differences in visual assessments or vegetation indices were observed between conventionally treated leaves and leaves treated according to the DSS. In the first year of this study two fungicide treatments were eliminated, in the second one fungicide treatment was eliminated. This finding is important because it provides evidence that plant health status is similar between conventionally sprayed trees and trees on a DSS-guided reduced spray program. In addition, the use of spectroradiometers for assessing the efficacy of different fungicide programs was demonstrated. Finally, potassium bicarbonate tankmixed with sulfur was confirmed to be an effective spray material for managing apple scab. By integrating the precise information provided by DSSs and the use of biorational pesticides, agricultural producers, service providers and educators are able to adapt climate change considerations and action-oriented decisions into pest management plans.
\end{abstract}

\section{Keywords}

Integrated Pest Management, Decision Support System, Pathogens, Fungicide, 


\section{Introduction}

Hyperspectral spectroradiometers can be used to capture more information on different light bands, allowing for identification of plant health status. The solarreflected optical spectrum spans a wavelength range from 400 to $3000 \mathrm{~nm}$ [1]. Of this range, the 400 to $2500 \mathrm{~nm}$ region is routinely measured using a variety of optical sensors varying from multispectral (for example, Landsat TM and OLI) to hyperspectral (for example, AVIRIS) [1]. The relationship between plant growth and spectral response in the visible and infrared wavelengths has been well established using the ratio of red and infrared reflectance, or other indices based on this ratio [2] [3]. Early research with color and color infrared aerial photos demonstrated that a number of crop infestations could be detected in the photographs including apple scab, wheat stem rust, corn leaf blight, and root rot in field beans [4]. Stress caused by the disease infestation results in reflectance changes in the vegetation, which can then be detected with remote sensing data [5]. Remote sensing refers to the use of sensor technologies to acquire information about an area-of-interest without making physical contact.

Vegetation reflectance properties are used to derive vegetation indices (VIs). VIs are constructed from reflectance measurements in two or more wavelengths across the optical spectrum to analyze specific characteristics of vegetation, such as total leaf area, chlorophyll content and water content [6] [7]. For different properties and field conditions, some indices within a category provide results with higher validity than others. By comparing the results of different VIs in a category, and correlating these to field conditions measured on site, one can assess which indices in a particular category perform the best at modelling the variability in the scene [1].

Apple scab, caused by the ascomycete Venturia inaequalis (Cooke) G. Winter (conidial stage: Spilocaea pomi), is a globally important disease in the production of apples as measured by economic loss, the cost and amount of fungicides necessary to control the disease, and the environmental impact of control measures [8]. Apple scab occurs wherever apples are grown and can be severely destructive in areas where spring weather is mild and conditions are wet. It is difficult to produce apples commercially without an effective fungicide program to control apple scab. $V$. inaequalis reproduces asexually during spring and summer and sexually during winter-spring. Sexual reproduction occurs between strains of opposite mating types that have infected the same leaf. The fungus overwinters in the leaves remaining on the ground on the orchard floor. The ascospores, which are the primary inoculum, mature during spring and are discharged during rain events [8].

Timing of fungicide applications during the primary infection season is critical 
to prevent apple scab with calendar-based spray programs often beginning at silver-tip, the growth stage immediately following dormant period. In many cases, failures in scab control during primary scab season in the spring cannot be ameliorated by fungicide applications later in the season [9]. The epidemiology of $V$. inaequalis during primary infections (until the end of ascospore release) and during secondary infections (in summer) is well documented [8] [10] [11] and decision support systems based on meteorological data can be used to apply fungicides timely for the prevention of apple scab [8].

While understanding the weather variables that are important for inoculum production, growers in the Northeast are also contending with the consequences of climate change and variability in climate patterns. Recent trends in climate variability in the northeastern U.S. have revealed an increase of high intensity rainfall events experienced each year [12]. This development is likely to cause apple production to continue to rely on the prophylactic use of fungicides for the control of apple scab. One practice that conventional and organic growers alike can readily adapt into their integrated pest management (IPM) plan is the use of Decision Support Systems (DSSs).

The Mills system is a model usually presented as a table or figure for predicting three levels of infection by ascospores on the basis of temperature and the duration of leaf wetness, and the criterion that the time required for infection by conidia is about one-third shorter than that indicated in the table for infection by ascospores [13]. Numerous decision support systems are currently available for assessing $V$. inaequalis primary infection risks, with RIMpro being the scab model of interest in this study. RIMpro is a set of models for management of pests and diseases of fruit that was first developed by Marc Trapman in 1993 (RIMpro B.V., Zoelmond, NL). RIMpro's initial aim was to produce an apple scab infection simulation tool that would provide a better epidemiological approach than that offered by Mills system alone, that could run with any weather station and that would be easy for growers and orchard consultants to use [14]. Presently, RIMpro contains disease simulation models for apple and pear scab (Figure 1), fire blight, powdery mildew, sooty blotch, apple canker, and Marssonina blotch, in addition to simulation models for apple insects and grape diseases. RIMpro models were developed in close collaboration with a project or expert group on the pest or disease in question and with the potential end-users of the DSS.

The number of fungicide treatments per year is timed by RIMpro; this timing depends on the climate in an individual year. In some years there is no reduction in the total number of fungicide treatments applied, but optimal timing of fungicide applications provides excellent control of apple scab. Despite the availability of various simulation models to aid the management of scab, the practice of using DSSs has not been widely adopted to date. Instead, many growers rely on a calendar-based spray program. Calendar-based spraying starts at silver-tip and continues at intervals based on the label of the products being applied or by 


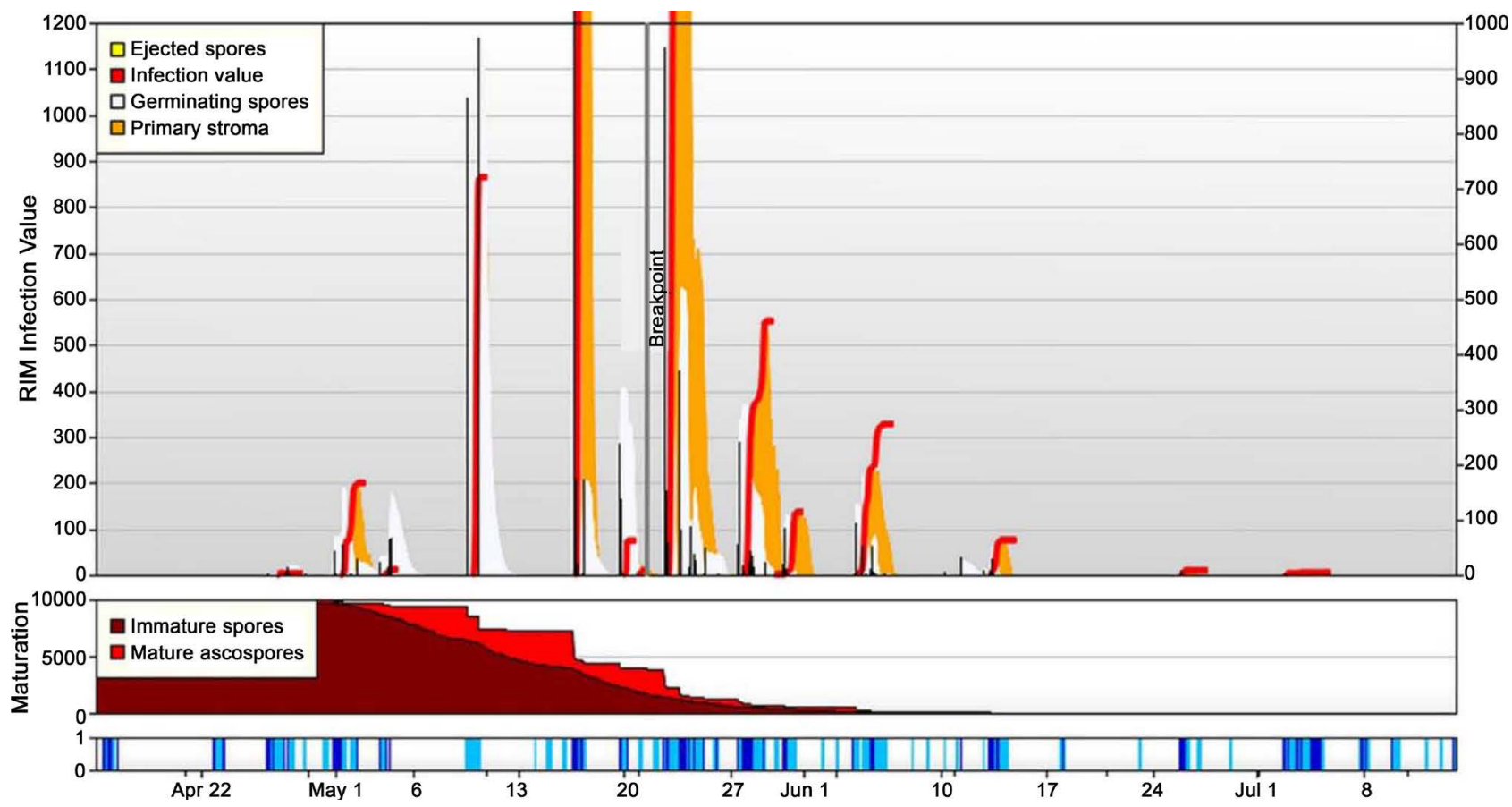

Figure 1. Overview of the RIMpro graphical user interface.

the growth stage of the apple tree until primary scab season is completed, typically around petal-fall [15]. In low scab risk orchards some growers delay sprays as late as pink, the stage at which all blossom buds in the cluster are pink and, the stems are fully extended [15]. Following petal-fall, growers move to cover sprays for the rest of the season, keeping the trees protected until harvest.

Historically, growers have relied on the Mills system in conjunction with calendar-based spray programs. Unfortunately, the prophylactic use of fungicides for the control of apple scab and a failure to rotate between classes of fungicides between applications has led to the development of $V$. inaequalis populations that are resistant to an increasing number of fungicides in major applegrowing areas [16] [17]. These fungicide-resistant populations demonstrate the unsustainability of calendar-based spray programs.

The overall objective of this study was to investigate if leaves treated according to the DSS were spectrally similar to leaves treated according to a calendar-based spray program, while being spectrally unique from untreated leaves. Specifically, the objective was to assess plant health status by identifying a suite of VIs that could be used to determine if leaves treated according to the DSS had similar spectral reflectance properties to conventionally treated leaves.

\section{Materials and Methods}

\subsection{RIMpro Implementation}

To run RIMpro, a Biofix (starting point) and local weather data are needed to initiate the calculations. Biofix is the date when the first ascospores in nature are observed to be mature and ready for discharge at the next rain event [6]. This 
moment can be established accurately by making regular observations of the development of pseudothecia under a microscope, or by wetting leaves and monitoring the ability of the pseudothecia to eject spores. The Biofix date can also be defined from the first ascospore projection as monitored in the field. In this case, Biofix should be set a few days before the date when the first spores were observed. If none of this information is available, Biofix is set to the date of green tip of the main apple variety (usually McIntosh in the Northeast), presuming a similarity between development of the fungus and the host due to coevolution. In most apple production regions, the Biofix date is found to be a date within a few days of green tip of apple. Local weather data requirements for RIMpro include measures of temperature, relative humidity, rainfall and leaf wetness (Figure 1). The weather station used in this study was an iMetos IMT200 with two leaf wetness sensors (Pessl Instruments. Weiz, Austria). The weather station was located in the center of the study site. Weather data were transmitted to the FieldClimate network by use of a cellular telemetry (GSM) connection. RIMpro automatically retrieves weather data from FieldClimate servers every 30 minutes.

The research was conducted at the University of New Hampshire's Kingman Farm located in Madbury, NH (43.168676, -70.934304) in a stand of mature McIntosh trees over the course of the 2013 and 2014 growing seasons. The stand had been unmanaged for the past 12 years and, due to high levels of $\mathrm{V}$. inaequalis, was utilized as an inoculum source for other experiments and represents an ideal high inoculum sites to evaluate management strategies. Pruning the orchard back into a managed state occurred over the winter of 2012-2013. Due to being unmanaged for an extended period of time, apple scab inoculum levels were considered extremely high at the study site. The experimental design was a randomized complete block design (RCBD) with two trees per plot for each treatment and three replications. A buffer row separated individual treatments with at least one tree between treatments in the same row. The experimental design included four treatments: $1=$ untreated; 2 = calendar-based $5 \mathrm{~kg} / \mathrm{ha}$ Captan 50 WG (48.0\% Captan, Micro Flo Co., Sparks, GA); 3 = 5 kg/ha Captan 50 WG (48.0\% Captan, Micro Flo Co., Sparks, GA) applied according to RIMpro forecasted infection events; and $4=5 \mathrm{~kg} /$ ha potassium bicarbonate USP (KBC) (Armand Products Co., Princeton, NJ) + 5 kg/ha Kumulus DF ( $80 \%$ sulfur, BASF Corp., Florham Park, NJ) applied according to RIMpro forecasted infection events. In 2014 Fontelis (20.4\% penthiopyrad, DuPont, Research Triangle Park, NC) was added as a tank-mix to the last two of the four sprays made during the primary scab-season for the Captan calendar-based treatment (TRT2). Calendarbased sprays were initiated at green-tip and continued at five to seven day intervals until petal-fall.

Fungicide applications were made using a Solo 451 Motorized Mist Blower (Solo. Newport News, VA) calibrated to apply at the rate of 35 gallons per acre. Sprays were made according to RIMpro predictions whenever an infection period was predicted or when the predicted RIM value exceeded 300 (Figure 1). 
RIM-infection values below 100 are regarded as slight, between 100 and 300 moderate, and over 300 as severe infection events. The RIM value is the red line in the graphic as read on the left axis of the main graph; it will not appear until an infection is in progress (Figure 1). The general rule is that if an orchard had no significant leaf scab in the previous year, then RIM infection values below 300 probably are not worth spraying. If an orchard had high levels of scab in the previous season, then a grower might want to spray when RIMpro shows lesser risk levels. For the $\mathrm{KBC}+\mathrm{S}$ treatment, depending on the severity of the infection period (RIM value $<900$ ), multiple applications of $\mathrm{KBC}+\mathrm{S}$ were made in what is known as the sandwich method. This is where applications are made before a predicted infection period, during the infection period and immediately following the infection period [18].

\subsection{Disease Assessment}

Foliar scab severity, quantified as number of lesions per leaf, was assessed on August 14 in 2013 and September 29 in 2014. In addition to visual assessment, measures of reflectance were recorded. Apple leaf reflectance measurements were obtained by scanning six stacks of seven leaves with three scans per stack taken at 0,90 and $270^{\circ}$ using a GER3700 (GER. Poughkeepsie, NY) in 2013 and an ASD FieldSpec4 in 2014 (ASD. Boulder, CO) with the aid of a hemispherical halogen light source mounted at a $45^{\circ}$ angle with the distance of the light source from the sample being equidistant to the distance of the sensor to the sample. Vegetation index means were calculated and Pairwise comparisons of leastsquare means was completed by using Tukey's honestly significant differences (HSD) test using the GLM procedure in SAS 9.4 (SAS Institute, Cary, NC). All significant differences were determined at the 0.05 level of significance.

\subsection{Vegetation Index Evaluation}

Vegetation indices evaluated include NDVI [19], REIP [20], NIR3/1 [21], MSI [7], Scab Index 1 [22], Scab Index 2 [22], Green Peak [23], Red Edge [24], and ZTM [25]. Vegetation indices based on water content, chlorophyll and stress were selected because apple scab infection affects these variables. Descriptions, computation and references for each index are provided in Table 1. The spectral reflectance data compliments the visual scab ratings and provides finer scale quantitative data than visual assessments alone.

\section{Results}

\subsection{RIMpro Effectiveness}

The intensity of apple scab severity was similar among years with the overall level of disease on unsprayed apples being 5.4 and 4.8 lesions per leaf for 2013 and 2014, respectively. Averaged across years, the mean number of lesions for unsprayed McIntosh apple leaves was 4.9 lesions per leaf, and mean number of 
Table 1. Description of the vegetation indices produced from reflectance measurements comparing untreated apple leaves to several fungicide programs.

\begin{tabular}{cccc}
\hline Index & Reference & Related to & Computation $^{\ddagger}$ \\
\hline NDVI & Rouse et al. $(1974)$ & Chlorophyll, stress & $((\mu \mathrm{R} 760-900)-(\mu \mathrm{R} 630-690)) /((\mu \mathrm{R} 760-900)+(\mu \mathrm{R} 630-690))$ \\
REIP & Rock et al. (1988) & Chlorophyll, stress & $\mathrm{R} 740^{*}((((\mathrm{R} 680+780) / 2)-700) /(\mathrm{R} 740-700))$ \\
NIR3/1 & Vogelman and Rock (1986) & Water content & $(\mu \mathrm{R} 1250-1325) /(\mu \mathrm{R} 794-900)$ \\
MSI & Hunt and Rock (1989) & Water content & $(\mathrm{R} 1550-1750) /(\mathrm{R} 760-800)$ \\
Scab Index 1 & Delalieux et al. (2009) & Apple Scab, Chlorophyll & $\mathrm{R} 440 / 690$ \\
Scab Index 2 & Delalieux et al. (2009) & Apple Scab, Stress & $\mathrm{R} 695 / 760$ \\
Green Peak & Thenkabail et al. (2000) & Chlorophyll, Stress & $\mathrm{R} 555$ \\
Red Edge & Merton et al. (1999) & Chlorophyll, Stress & $\mathrm{R} 740-710$ \\
ZTM & Zarco Tejada et al. (2001) & Chlorophyll, Stress & $\mathrm{R} 750 / \mathrm{R} 710$ \\
\hline
\end{tabular}

${ }^{\dagger} \mathrm{NDVI}=$ normalized difference vegetation index; REIP = red edge inflection point; NIR3/1 = near-infrared 3/1, MSI = moisture stress index, ZTM = Zarco-Tejada \& Miller. ${ }^{*} \mathrm{R}$ in computation represents reflectance and $\mu$ represents average.

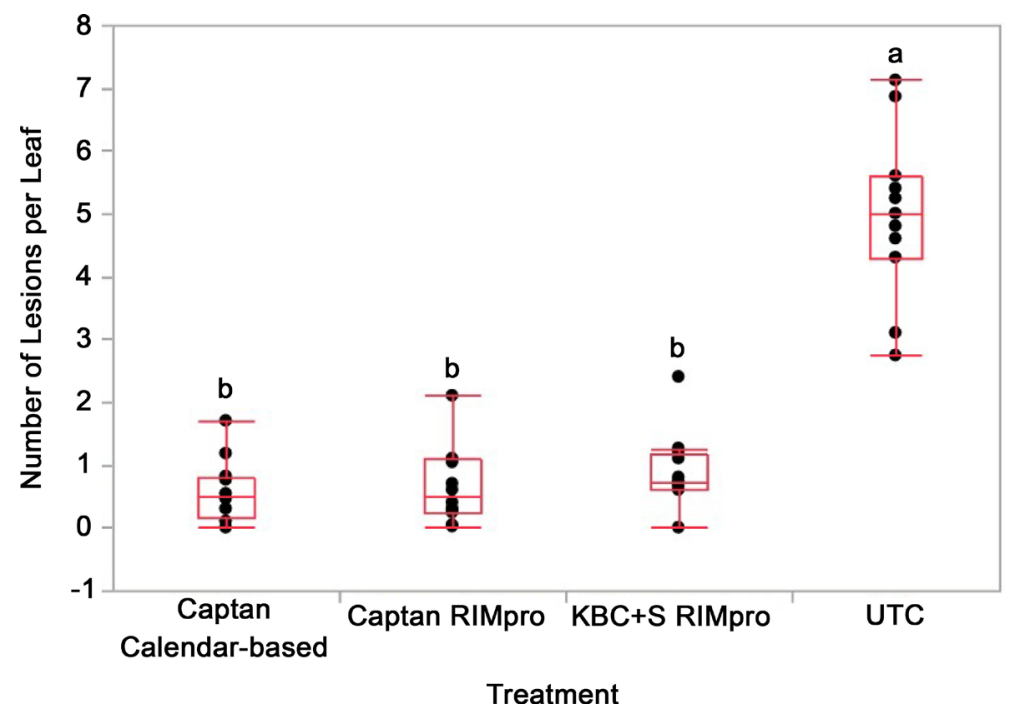

Figure 2. Boxplot for 2013 and 2014 RIMpro trials (data combined) comparing fungicide treatment program to average number of lesions per leaf. Boxplots with different letters differ significantly (Tukey's HSD, $\mathrm{p} \leq 0.05$ ).

lesions for fungicide treated leaves was 0.71 per leaf. Among the individual fungicide treatments, the number of lesions per leaf was nearly the same with 0.58 lesions per leaf for Captan applied with a Calendar-spray program, 0.66 lesions per leaf for Captan applied according to RIMpro's predictions, and 0.90 lesions per leaf for potassium bicarbonate + sulfur applied according to RIMpro's predictions. In both years, all treated plots had lower mean levels of apple scab estimated as number of lesions per leaf with either Captan applied with a calendar spray program or Captan applied according to RIMpro generally having the lowest levels of disease severity (Figure 2). All three fungicide treatments were significantly different from the untreated control $(\mathrm{p} \leq 0.05)$. 

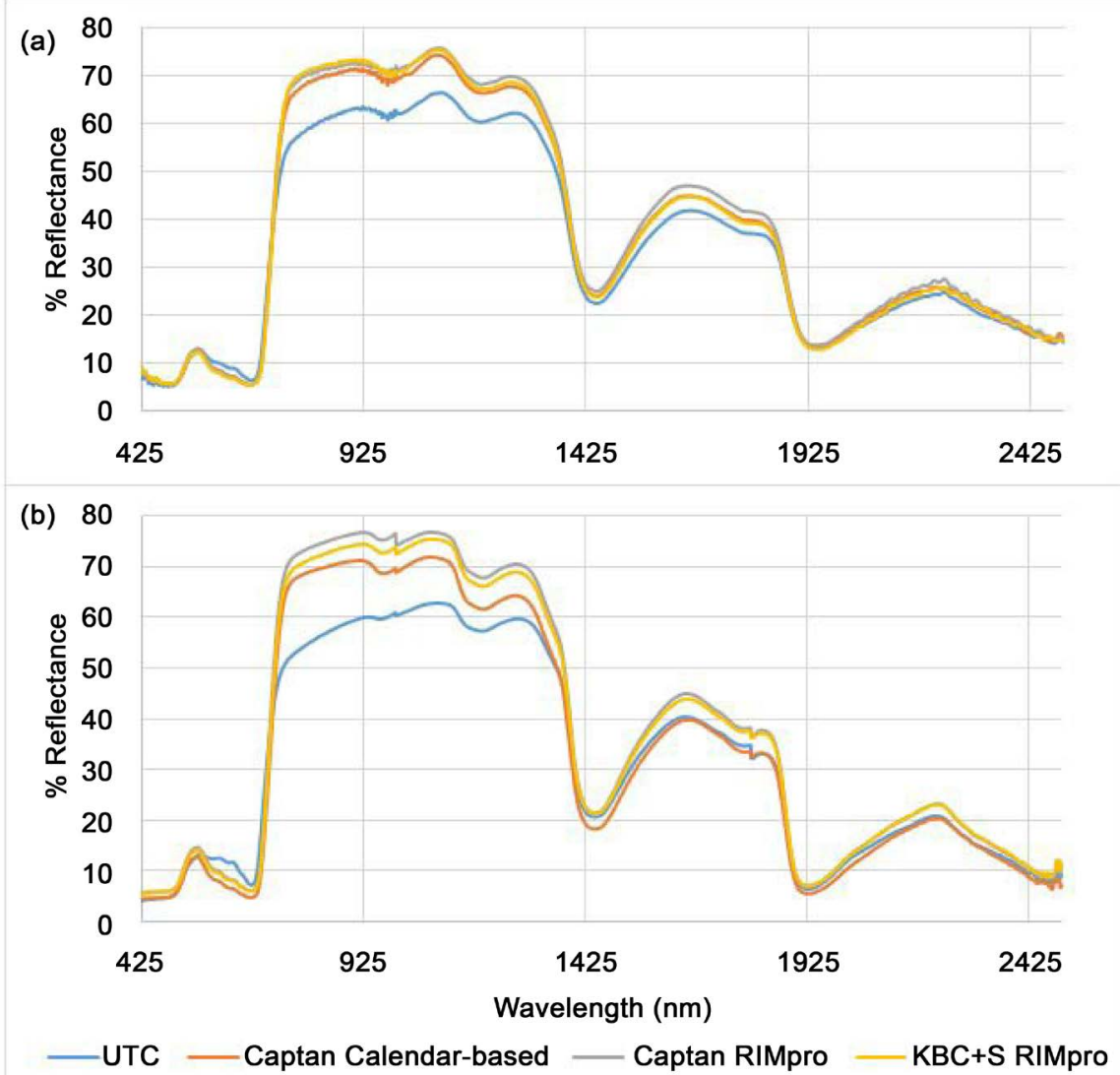

Figure 3. Average apple leaf reflectance measurements comparing fungicide treated apple leaves and unsprayed apple-scab infected leaves (UTC) for the 2013 (a) and 2014 (b) growing seasons.

There was no significant difference between any of the three fungicide treatments ( $p \geq 0.05$ ) (Figure 2). This can also be observed in Figure 3 where reflectance curves comparing fungicide treated apple leaves and unsprayed apple-scab infected leaves are shown. The blue line (UTC) represents the untreated control and differences in reflectance values can be observed within the $568-686 \mathrm{~nm}$ (red chlorophyll-well) and $735-1370 \mathrm{~nm}$ (near-infrared or NIR) regions of the spectrum.

\subsection{Fungicide Effects}

For both 2013 and 2014, fungicide treatment had a significant effect on the number of apple scab lesions per leaf (Figure 3). The treatment $\mathrm{x}$ block effect was not significant in either year. Based on mean separation tests and Pairwise comparisons between treatments, there was no statistical difference $(p>0.05)$ between the three spray programs (TRT2-4) used in either year of the study. In 2014, although treatments where Captan was used generally had fewer average lesions per leaf, they were not significantly different from the number of lesions per leaf when $\mathrm{KBC}+\mathrm{S}$ was applied according to RIMpro. 


\subsection{Fungicide Applications}

Throughout the 2013 primary scab season the Captan Calendar treatment (TRT2) received seven applications, Captan applied according to RIMpro (TRT3) received five applications and the $\mathrm{KBC}+\mathrm{S}$ applied according to RIMpro (TRT4) received eight applications.

Throughout the 2014 primary scab season the Captan Calendar treatment (TRT2) received four applications. Fontelis was added as a tank-mix to the latter two of the four sprays for the Captan Calendar treatment (TRT2). Captan applied according to RIMpro (TRT3) received three applications and the $\mathrm{KBC}+\mathrm{S}$ applied according to RIMpro (TRT4) also received three applications. Overall, the total number of sprays using the RIMpro apple scab model was reduced by two applications in 2013 and one application in 2014 as compared to the calendarbased spray program (28\% and 25\% reduction in sprays for 2013 and 2014, respectively).

\subsection{Vegetative Indices vs Apple Leaf Health}

Evaluations of vegetation indices; NDVI, REIP, NIR3/1, MSI, Scab Index 1, Scab Index 2, Green Peak, Red Edge, and ZTM showed significant differences ( $\mathrm{p} \leq$ $0.05)$ in reflectance properties between fungicide treated apple leaves and untreated apple leaves except for Green Peak (Table 2).

\section{Discussion}

Following completion of this research we have confirmed that a practice that conventional and organic grower alike could readily adapt into their IPM plan is the use of RIMpro. Decision support systems such as RIMpro have been shown to provide effective apple scab control. The number of fungicide treatments per year is timed by RIMpro; this timing depends on the actual climate in an

Table 2. Vegetation indices produced from reflectance measurements comparing untreated apple leaves to several fungicide programs.

\begin{tabular}{ccccccccc}
\hline Index & Unsprayed & $\dagger$ & $\begin{array}{c}\text { Captan } \\
\text { Calendar-based }\end{array}$ & $\dagger$ & $\begin{array}{c}\text { Captan } \\
\text { RIMpro }\end{array}$ & $\begin{array}{c}\text { KBC }+ \text { S } \\
\text { RIMpro }\end{array}$ \\
\hline NDVI & 0.72 & $\mathrm{~b}$ & 0.86 & $\mathrm{a}$ & 0.83 & $\mathrm{a}$ & 0.83 & $\mathrm{a}$ \\
REIP & 713 & $\mathrm{~b}$ & 721 & $\mathrm{a}$ & 719 & $\mathrm{a}$ & 720 & $\mathrm{a}$ \\
NIR3/1 & 1.04 & $\mathrm{a}$ & 0.90 & $\mathrm{c}$ & 0.93 & $\mathrm{bc}$ & 0.93 & $\mathrm{~b}$ \\
MSI & 0.68 & $\mathrm{a}$ & 0.53 & $\mathrm{c}$ & 0.56 & $\mathrm{~b}$ & 0.57 & $\mathrm{~b}$ \\
Scab Index 1 & 0.38 & $\mathrm{~b}$ & 0.73 & $\mathrm{a}$ & 0.73 & $\mathrm{a}$ & 0.74 & $\mathrm{a}$ \\
Scab Index 2 & 0.31 & $\mathrm{a}$ & 0.12 & $\mathrm{~b}$ & 0.15 & $\mathrm{~b}$ & 0.15 & $\mathrm{~b}$ \\
Green Peak & 0.13 & $\mathrm{a}$ & 0.12 & $\mathrm{a}$ & 0.14 & $\mathrm{a}$ & 0.14 & $\mathrm{a}$ \\
Red Edge & 0.17 & $\mathrm{~b}$ & 0.35 & $\mathrm{a}$ & 0.35 & $\mathrm{a}$ & 0.34 & $\mathrm{a}$ \\
ZTM & 1.61 & $\mathrm{c}$ & 2.66 & $\mathrm{a}$ & 2.37 & $\mathrm{~b}$ & 2.44 & $\mathrm{ab}$ \\
\hline
\end{tabular}

'Index means followed by different letters within a row differ significantly (Tukey's HSD, $\mathrm{p} \leq 0.05$ ). 
individual year. In the first year of this study two fungicide treatments were eliminated, in the second one fungicide treatment was eliminated. While RIMpro was shown to be effective at reducing the total number of sprays in a season, it is not the only DSS that growers located in the northeastern U.S. could choose to implement. Other DSS's that growers could choose to use include NEWA, SkyBit and AgRadar [26] [27] [28].

Results of the study confirm that excellent control of apple scab is possible as long as an effective spray program is in place and that RIMpro is a suitable DSS to be used to support the IPM decision making process. RIMpro was able to reduce the total number of spray applications made during the primary scab season by two sprays in 2013 and one spray in 2014. An accurate Biofix date continues to be of utmost importance when deciding when to start the model each season, the Biofix date between the two years of the study was similar occurring on April 22 in 2013 and April 25 in 2014. While KBC + S applied according to RIMpro received the greatest number of fungicide applications throughout the growing season it should be noted that the spray materials used are relatively low-cost as compared to conventional synthetic spray materials.

The use of spectroradiometers to assess the reflectance properties of apple leaves was shown to be useful in this study. Both the increased reflectance in the red chlorophyll-well and the narrowing of that well are indicative of reduced amounts of chlorophyll in the untreated control, while the lower reflectance values in the near-infrared region indicate that the untreated leaves are less healthy than fungicide treated leaves [6] [20]. These differences are especially pronounced in the 2014 reflectance curves (Figure 3(b)). Because NIR wavelengths of solar radiation are not absorbed by any pigments within the plant, they travel through most of the leaf and interact with both the palisade and spongy mesophyll cells [6] [29]. This interaction (transmission and refraction) causes about half of the energy to be reflected and the other half to be transmitted through the leaf [29] [30].

In plants with turgid and healthy mesophyll cell walls and in dense canopies, more NIR energy will be reflected and less transmitted [29]. This cell wall/air space interaction within these cells causes healthy vegetation to look very bright in the NIR. In fact, much more NIR is reflected than in the visible, due to the strong absorption in the visible by chlorophylls and other plant pigments. By monitoring the amount of NIR and visible energy reflected from the plant, it is possible to determine the health of the plant [30].

Vegetation indices (NDVI, REIP, NIR3/1, MSI, Scab Index 1, Scab Index 2, Red Edge and ZTM) generated from data collected using spectroradiometers show that apple leaves that were treated with a fungicide during primary scab season were healthier than leaves left unsprayed. These vegetation indices compliment data collected in this study showing that untreated apple leaves had a greater number of lesions per leaf when compared to fungicide treated leaves.

Our study confirms the results of Delalieux et al. [22] where the group identi- 
fied two vegetation indices that were superior for distinction of scab infected leaves and non-infected leaves (Table 2). These two indices were R440/R690 and R695/R760 and have been confirmed to excel at distinguishing healthy from scab-infected apple leaves (Table 2). Additional indices that were found to be useful for distinguishing apple scab infected leaves from non-infected leaves include; NDVI, REIP, NIR3/1, MSI, Red Edge and ZTM (Table 2). The only value or biophysical indicator evaluated that was found to be unable to distinguish healthy from infected apple leaves was the Green Peak $(555 \mathrm{~nm})$ which is the reflectance value for a single band at $555 \mathrm{~nm}$ (Table 2).

The impact on high intensity rainfall events on the epidemiology of the apple scab pathogen warrants further investigation. It would be expected that high intensity rainfall events early in the primary scab season would shorten the duration of primary scab season in orchards due to early depletion of ascospores. The effect of a high intensity rainfall event inducing ascospore depletion was observed in the second year of this study where after the third infection event RIMpro predicted that the asci would have released all their ascospores. This is despite the fact three additional infections periods were predicted following the rain event where RIMpro predicted that all ascospores had been released. For both 2013 and 2014, RIMpro predicted seven infection events during primary scab season. The model seems to have been accurate as fungicide applications for primary scab ceased following the third infection event in 2014, and average disease levels were similar to those observed in 2013 when sprays continued for the entire primary scab season.

\section{Conclusions}

The results from this investigation confirmed the importance of having an effective spray program in place and the usefulness of DSSs such as RIMpro. DSSs help agricultural producers, service providers and educators by integrating climate change considerations and action-oriented decisions into pest management plans. The similarity in visual assessments and reflectance properties among the fungicide treated leaves show that leaves treated according to the DSS have similar spectral properties to those treated conventionally, while being spectrally unique from leaves left unsprayed. This finding is important because it provides evidence that plant health status is similar between conventionally sprayed trees and trees on a DSS-guided reduced spray program. Therefore, when a DSS recommends reducing the number of applications during primary scab season, a grower could do so, knowing that effective management of apple scab is possible.

In addition, the potassium bicarbonate + sulfur treatment $(\mathrm{KBC}+\mathrm{S})$ demonstrated the same level of control as Captan used alone or when tank-mixed with Fontelis. This finding supports the results and conclusions of Holb and Kunz's 2016 study [31]. Their results indicated that potassium bicarbonate treatments significantly reduced apple scab during the primary infection period compared with untreated plots and concluded that potassium bicarbonate in combination 
with wettable sulfur and integration with pruning and whole-orchard sanitation treatments can be an environmentally safe and viable option for scab control in organic apple production [31]. Our study provided further evidence that $\mathrm{KBC}+$ $\mathrm{S}$ is a suitable candidate for use in organic orchard operations or for those interested in using low-cost, low-hazard alternative spray materials as part of their IPM program.

\section{Acknowledgements}

We thank John McLean and Evan Ford for their assistance and support in the field. This study was supported in part by the University of New Hampshire's Agricultural Experiment Station and by funds provided by USDA NIFA SCRI (Grant No. 2009-51181-06002).

\section{Disclosure Statement}

The use of trade, firm, or corporation names in this publication is for the information and convenience of the reader. Such use does not constitute an official endorsement or approval by the United States Department of Agriculture or the Agricultural Research Service of any product or service to the exclusion of others that may be suitable.

\section{References}

[1] Asner, G. (1998) Biophysical and Biochemical Sources of Variability in Canopy Reflectance. Remote Sensing of Environment, 64, 234-253. https://doi.org/10.1016/S0034-4257(98)00014-5

[2] Jackson, R.D. (1984) Remote Sensing of Vegetation Characteristics for Farm Management. SPIE Proceedings, 475, 81-96.

[3] Bauer, M. (1985) Spectral Inputs to Crop Identification and Condition Assessment. Proceedings of the IEEE, 73, 1071-1085. https://doi.org/10.1109/PROC.1985.13238

[4] Hatfield, P. and Pinter, P. (1993) Remote Sensing for Crop Protection. Crop Protection, 12, 403-413. https://doi.org/10.1016/0261-2194(93)90001-Y

[5] Garcia-Ruiz, F., Sankaran, S., Mari Maja, J., Lee, W., Rasmussen, J. and Ehsani, R. (2013) Comparison of Two Aerial Imaging Platforms for Identification of Huanglongbing-Infected Citrus Trees. Computers and Electronics in Agriculture, 91, 106-115. https://doi.org/10.1016/j.compag.2012.12.002

[6] Rock, B., Vogelmann, J., Williams, D., Vogelmann, A. and Hoshizaki, T. (1986) Remote Detection of Forest Damage. BioScience, 36, 439-445.

https://doi.org/10.2307/1310339

[7] Hunt, E. and Rock, B. (1989) Detection of Changes in Leaf Water Content Using Near- and Middle-Infrared Reflectances. Remote Sensing of Environment, 30, 43-54. https://doi.org/10.1016/0034-4257(89)90046-1

[8] MacHardy, W. (1996) Apple Scab: Biology, Epidemiology, and Management. APS Press, St. Paul, MN.

[9] Köhl, J., Scheer, C., Holb, I., Masny, S. and Molhoek, W. (2015) Toward an Integrated Use of Biological Control by Cladosporium cladosporioides H39 in Apple Scab (Venturia inaequalis) Management. Plant Disease, 99, 535-543. 
https://doi.org/10.1094/PDIS-08-14-0836-RE

[10] Carisse, O., Philion, V., Rolland, D. and Bernier, J. (2000) Effect of Fall Application of Fungal Antagonists on Spring Ascospore Production of the Apple Scab Pathogen, Venturia inaequalis. Phytopathology, 90, 31-37. https://doi.org/10.1094/PHYTO.2000.90.1.31

[11] Holb, I., Heijne, B., Withagen, J., Gáll, J. and Jeger, M. (2005) Analysis of Summer Epidemic Progress of Apple Scab at Different Apple Production Systems in the Netherlands and Hungary. Phytopathology, 95, 1001-1020.

https://doi.org/10.1094/PHYTO-95-1001

[12] Pachauri, R.K., Allen, M.R., Barros, V.R., Broome, J., Cramer, W., Christ, R., Dubash, N.K., et al. (2014) Climate Change 2014: Synthesis Report. Contribution of Working Groups I, II and III to the Fifth Assessment Report of the Intergovernmental Panel on Climate Change. IPCC, Geneva, 1-151.

[13] MacHardy, W.E. and Gadoury, D.M. (1989) A Revision of Mills Criteria for Predicting Apple Scab Infection Periods. Phytopathology, 79, 304-310.

https://doi.org/10.1094/Phyto-79-304

[14] Trapman, M. and Polfliet, M. (1997) Management of Primary Infections of Apple-Scab with the Simulation Program RIMpro: Review of Four Years Field Trials. IOBC wprs Bulletin, 20, 241-250.

[15] Chapman, P. and Catlin, G. (1976) Growth Stages in Fruit Trees-From Dormant to Fruit Set. New York's Food and Life Sciences Bulletin, 58, 1-11.

[16] Beresford, R., Wright, P., Wood, P., Park, N., Larsen, N. and Fisher, B. (2013) Resistance of Venturia inaequalis to Demethylation Inhibitor and Dodine Fungicides in Four New Zealand Apple-Growing Regions. New Zealand Plant Protection, 66, 274-283.

[17] Fiaccadori, R., Cicognani, E., Alberoni, G., Collina, M. and Brunelli, A. (2011) Sensitivity to Strobilurin Fungicides of Italian Venturia inaequalis Populations with Different Origin and Scab Control. Pest Management Science, 67, 535-540. https://doi.org/10.1002/ps.2090

[18] Trapman, M., Triloff, P., Philion, V. and Scholffer, K. (2012) The European Apple Scab Sandwich. The European Fruit Magazine, 2012, 4.

[19] Rouse Jr, J., Haas, R., Schell, J. and Deering, D. (1974) Monitoring Vegetation Systems in the Great Plains with ERTS. NASA Special Publication, 351, 309.

[20] Rock, B., Hoshizaki, T. and Miller, J. (1988) Comparison of in Situ and Airborne Spectral Measurements of the Blue Shift Associated with Forest Decline. Remote Sensing of Environment, 24, 109-127. https://doi.org/10.1016/0034-4257(88)90008-9

[21] Vogelmann, J. and Rock, B. (1986) Assessing Forest Decline in Coniferous Forests of Vermont using NS-001 Thematic Mapper Simulator Data. International Journal of Remote Sensing, 7, 1303-1321. https://doi.org/10.1080/01431168608948932

[22] Delalieux, S., Somers, B., Verstraeten, W., van Aardt, J., Keulemans, W. and Coppin, P. (2009) Hyperspectral Indices to Diagnose Leaf Biotic Stress of Apple Plants, Considering Leaf Phenology. International Journal of Remote Sensing, 8, 1887-1912. https://doi.org/10.1080/01431160802541556

[23] Thenkabail, P., Smith, R. and De Pauw, E. (2000) Hyperspectral Vegetation Indices and Their Relationships with Agricultural Crop Characteristics. Remote Sensing of Environment, 71, 158-182. https://doi.org/10.1016/S0034-4257(99)00067-X 
[24] Merton, R. (1999) Multi-Temporal Analysis of Community Scale Vegetation Stress with Imaging Spectroscopy. PhD Thesis, Department of Geography, University of Auckland, Auckland.

[25] Zarco-Tejada, P., Miller, J., Noland, T., Mohammed, G. and Sampson, P. (2001) Scaling-Up and Model Inversion Methods with Narrowband Optical Indices for Chlorophyll Content Estimation in Closed Forest Canopies with Hyperspectral Data. IEEE Transactions on Geoscience and Remote Sensing, 39, 1491-1507. https://doi.org/10.1109/36.934080

[26] Carroll, J., Weigle, T. and Petzoldt, C. (2009) The Network for Environment \& Weather Applications (NEWA). New York Fruit Quarterly, 19, 5-9.

[27] Koehler, G. (2007) Introduction to Ag-Radar. University of Maine Cooperative Extension.

[28] Russo, J.M. (1997) Site Specific Weather Forecasts for IPM Decision. Proceedings of the 3rd National IPM Symposium/Workshop: Broadening Support for 21 st Century IPM, Washington DC, 27 February-1 March 1996, 275-276.

[29] Gates, D., Keegan, H., Schleter, J. and Weidner, V. (1965) Spectral Properties of Plants. Applied Optics, 4, 11-20. https://doi.org/10.1364/AO.4.000011

[30] Stephens, C. and Rasmussen, P. (2010) On Target Near-Infrared Tutorial. Utah State University Extension, Logan.

[31] Holb, I. and Kunz, S. (2016) Integrated Control of Apple Scab and Powdery Mildew in an Organic Apple Orchard by Combining Potassium Carbonates with Wettable Sulfur, Pruning and Cultivar Susceptibility. Plant Disease, 100, 1894-1905.

https://doi.org/10.1094/PDIS-12-15-1416-RE 